\title{
Sistema Informacional: Gerenciando o Fluxo de uma Ferramenta Cognitiva
}

\author{
Aida Varela Varela ${ }^{1}$, Igor Baraúna ${ }^{2}$ \\ ${ }^{1}$ Universidade Federal da Bahia (UFBA) \\ varela@ufba.ba \\ ${ }^{2}$ Instituto de Radiodifusão Educativa da Bahia \\ igor.guimaraes@hotmail.com
}

\begin{abstract}
Resumo
Os novos contextos tecnológicos e científicos exigem outras capacidades que unem compreensivamente a leitura e a escrita, uma capacidade que se respalda não somente em destrezas e habilidades, senão, sobretudo, em competências. Este artigo apresenta uma experiência de gestão de um sistema de informação na área educacional - fluxo informacional e realimentação - cujo objetivo é o de acionar, acompanhar e avaliar a implementação de uma ferramenta cognitiva, construtivista e interacionista, a Teoria da Modificabilidade Cognitiva Estrutural (TMCE), em unidades escolares de Ensino Médio da Rede Pública Estadual da Bahia, Brasil. Experiência na qual se enfrentou o desafio para melhorar a qualidade do processo de ensino e aprendizagem, rumo ao fortalecimento do potencial humano.

Palavras-chave: sistema informacional, ferramenta cognitiva, cognição, potencial humano.
\end{abstract}

\begin{abstract}
The new technological and scientific surroundings demand other capacities that combine the reading and the writing comprehensively. Capacities that are based not only in skills and abilities, but mainly in competitions. This article presents an information system management experience in the educational area - informational flow and feedback - whose objective is to put in action, to accompany and to evaluate the implementation of a cognitional, constructive and interactive tool, the Instrumental Enrichment Program - PEI -, in public high school of Bahia, Brasil. Experience in which had faced the challenge to improve the quality of the education process and learning, towards a fortification of the human potential.

Key-words: information system, cognitive tool, cognition, human potential.
\end{abstract}

\section{Introdução}

As mudanças provocadas pela terceira revolução industrial - as novas tecnologias - criaram uma nova dinâmica mundial. $\mathrm{O}$ modo como o dado se transforma em informação e esta em conhecimento tem variado radicalmente no contexto tecnológico ciberespacial, amplamente universalizado e numa expansão exponencial. [8]

Desde meados do século XX, a formação de pessoas e de grupos, assim como de avanços científicos, técnicos e as expressões culturais estão em constante evolução, numa interdependência cada vez maior. $\mathrm{O}$ conhecimento é o elemento central de todas essas mutações e tem se convertido em objeto de imensos desafios econômicos, políticos e culturais, até o momento que as sociedades são qualificadas como sociedades do conhecimento.

O paradigma científico tradicional e o modelo disciplinar do conhecimento que o representava entraram em crise em meados do século XX, com o surgimento de objetos de estudo ou situações que não podiam ser explicadas a partir de uma visão disciplinar. Este fenômeno representou e representa uma profunda mudança de perspectiva e de pensar 
a realidade, que se inicia com a crise do modelo empirista da ciência e está diretamente enraizado no pensamento complexo. [12]

Este novo paradigma contrapõe-se à excessiva especialização que prevalece no desenvolvimento da ciência contemporânea, o que supõe uma fragmentação excessiva dos problemas da realidade e uma perda de contato com a mesma. Contrapõe-se ao reducionismo modernista e pretende modificar a forma de conhecer o entorno fazendo-o mais compatível com o ser humano.

A transformação dos paradigmas econômicos e produtivos afeta a divisão do trabalho e a percepção do lugar do indivíduo na organização, evidenciando a natureza cada vez mais complexa das situações de trabalho e a correspondente multidisciplinaridade, que tem afetado a empregabilidade e os perfis dos profissionais. [13] Os modelos organizacionais também vêm sofrendo alterações, enfatizando o trabalho em equipe, a cooperação, as parcerias e o estabelecimento de redes.

O foco central das sociedades do conhecimento é a capacidade para identificar, produzir, tratar, transformar, difundir e utilizar a informação com o objetivo de criar e aplicar conhecimentos para o desenvolvimento humano, propiciando a autonomia e englobando as noções de pluralidade, integração, solidariedade e participação. As questões relativas à tecnologia e à capacidade de conexão tornam-se basilares para administrar o universo das redes.

Chega-se a uma era em que para existir, sobreviver e não ficar à margem é necessário informar-se cada vez mais e, sobretudo, cada vez mais de maneira acelerada, interativa, características dos novos suportes informacionais, a exemplo da internet quando as competências informativas e cognitivas se desenvolvem em uníssono e estimulam os indivíduos a criar com toda a autonomia comunidades virtuais.

Pergunta-se, então, que educação é necessária aos cidadãos do nosso tempo, já que não são suficientes os conhecimentos básicos da lectoescrita e, sim, o saber manejar, com desenvoltura, alguns dos muitos aparatos tecnológicos da informação e comunicação que se tornam imprescindíveis.

Os aprendizes não estão sendo orientados para uma variada tipologia de materiais de leitura, numa multiplicidade de suportes e modalidades de informação. Um dos termos utilizado atualmente é o da alfabetização "digital", termo que presumidamente inclui todas aquelas capacidades e destrezas necessárias para desenvolver-se na sociedade da informação. Não se pode, sem dúvida, esquecer outra "alfabetização", que seria aquela que se propaga com força, em círculos, especialmente bibliotecários e que objetiva que as pessoas sejam capazes de buscar, localizar e usar a informação. Esse outro tipo de alfabetização - da família "digital" - vem sendo denominada de alfabetização informacional. [6]

Pode-se recorrer à definição de alfabetização informacional elaborada na reunião de especialistas que pro- mulgaram a Declaração de Praga: rumo a uma sociedade alfabetizada em informação:

A alfabetização informacional abarca o conhecimento das próprias necessidade e problemas concernentes à informação, e a capacidade para identificar, localizar, avaliar, organizar, criar, utilizar e comunicar com eficácia a informação para afrontar os problemas ou questões planejadas; é um prérequisito para a participação eficaz na sociedade da informação; e faz parte do direito humano básico à aprendizagem ao longo da vida. [3]

Para que se chegue à alfabetização informacional, recorrendo-se a vários autores, vários contextos e vários critérios de avaliação, estudiosos declaram e comprovam que os seres humanos têm potencial para desenvolver "competências informacionais". As práticas pedagógicas buscam mais do que nunca a transferência do foco de ensinoaprendizagem do docente para o aprendiz e dos conteúdos para os processos de aprendizado, enfatizando a formação integral do indivíduo: conhecimentos, habilidades e valores. [9] As mudanças na percepção dos processos educacionais perpassam pela criação de pontes entre a dimensão epistemológica (conhecimento), a dimensão pedagógica (ensinar e aprender) e a dimensão política (escolha do projeto de sociedade e escola que se pretende).

Neste artigo, será exposto como foi dado o processo de geração, disseminação e uso de uma teoria cognitivista, subsidiado pela gestão de um sistema informacional na área educacional, durante a implementação de um projeto pedagógico, respaldado pela Teoria da Modificabilidade Cognitiva Estrutural (TMCE), com foco na cognição, que defende a modificabilidade, a flexibilidade da estrutura cognitiva. $\mathrm{O}$ pressuposto desta Teoria é de que o ser humano é dotado de uma mente plástica, flexível, aberta a mudanças, assim como de um potencial e de uma propensão natural para a aprendizagem, comprovando que se pode desenvolver o potencial de leitura, de acordo com as exigências dos avanços tecnológicos e cognitivos.

\section{O Desafio da Qualidade}

A Lei de Diretrizes e Bases da Educação Nacional - LDB (Lei n. ${ }^{\circ}$ 9.394/96) busca conciliar Humanismo e Tecnologia, conhecimento dos princípios científicos que presidem a produção moderna, exercício da cidadania plena, formação ética e autonomia intelectual. Nesse cenário é preciso reconstruir o saber da Escola e a formação do educador na dimensão interdisciplinar e na diversidade cultural.

Em busca da qualidade em leitura em um Estado do Nordeste brasileiro, a Bahia, foram desenvolvidos vários estudos diagnósticos, destacando-se o da Fundação Carlos Chagas, no ano de 2000, realizado em escolas da Rede Pública Estadual e Municipal de ensino, totalizando 53.961 alunos concluintes do $8^{\circ}$ grau do Ensino Básico. 
Os resultados demonstraram que, em Língua Portuguesa, os alunos obtiveram um percentual de acertos abaixo de $50 \%$ em relação a: depreender de uma informação explícita outra informação implícita no texto; inferir o sentido de uma palavra ou de uma expressão considerando o contexto e/ou o universo temático e/ou a estrutura morfológica da palavra; reconhecer, em um texto, características que permitam identificar o interlocutor ou o personagem; relacionar informações; e identificar o tema/tópico central de um texto.

Já em Matemática, os alunos apresentaram dificuldade em compreender os enunciados das questões e lidar com a linguagem matemática; no que se refere à álgebra, eles restringem-se ao trabalho com equações em que a letra funciona apenas como incógnita; as frações não têm significado para eles e o conceito de números racionais não é de domínio desses alunos.

Ainda de acordo com a avaliação da Fundação Carlos Chagas, o principal problema que afeta o professor é a falta de recursos para a ação - entendidos na sua variedade de formação específica, tecnologias de ensino, acesso aos bens culturais e estratégias didáticas, entre outros - e, não tanto, a existência ou não de propostas curriculares, profundas ou superficiais, que o orientem. Noutras palavras, o que falta ao professor é um repertório científico e tecnológico que ultrapasse o do aluno, além de conhecimentos de Artes, de História das Ciências, de Filosofia. Entende-se que, assim, a interdisciplinaridade pode ser efetivada, além de que o professor precisa fortalecer mediações entre a cultura dos alunos, a cultura da comunidade e a cultura escolar [11]

A esta situação acrescenta-se o fato de que as estratégias com as quais conta a escola para orientar a seus alunos como leitores são instáveis e muitas vezes paradoxais. Por um lado, dispõe de aulas onde a leitura é condicionada à finalidade formativa implícita ao próprio ato de ler. E por outro, estão as bibliotecas escolares geralmente pouco utilizadas e infra-dotadas. Nas aulas, os alunos são considerados mais como aprendizes do que como leitores e nas bibliotecas mais leitores do que aprendizes, assim, a vinculação íntima entre leitura, aprendizagem, conhecimento e significado, não está sendo alcançada. [2]

É relevante, portanto, a reflexão sobre o grau de assimilação e compreensão da informação pelo sujeito, sob a ótica cognitiva, sem levar em consideração a construção de representações mentais e o desenvolvimento de competências e habilidades, no sentido de que mediador e mediado compreendam sua própria cultural e identifiquem as dimensões da realidade.

O retrato socioeconômico da juventude brasileira exige que a educação média atenda a uma dupla necessidade: direito a uma formação humanística geral de qualidade e acesso a conhecimentos humanísticos e específicos que utilizem a continuidade dos estudos e o ingresso na vida produtiva. Observe-se que, no atual estágio de construção do conhecimento pela humanidade, a dicotomia entre conhecimento geral e específico, entre ciência e técnica, ou mesmo a visão de tecnologia como mera aplicação da ciência, devem ser superadas de tal forma que a escola incorpore a cultura técnica e a cultura geral na formação plena dos sujeitos e na produção contínua de conhecimentos. [11]

\subsection{Em busca de estratégias de desenvolvimen- to de potencial}

Nos primeiros anos do século XX, a educação focalizava a aquisição das habilidades de letramento: leitura, escrita e cálculos básicos, sem, contudo, preparar as pessoas para pensar e ler criticamente e para solucionar problemas complexos de ciências e matemática. Atualmente, aspectos do letramento avançado são exigidos para que se possa lidar, com sucesso, com a complexidade da vida contemporânea. As exigências de qualificação para o trabalho aumentaram sensivelmente, assim como a necessidade de que as organizações e os trabalhadores mudem para atender às pressões competitivas do ambiente de trabalho. A participação consciente no processo democrático também se tornou cada vez mais complexa, à medida que o foco da atenção se deslocou do interesse local para o nacional e desse para o global.

Acima de tudo, as informações e o conhecimento crescem a um ritmo muito mais acelerado do que jamais visto na história da humanidade. A pessoa em vez de ser capaz de lembrar e repetir informações deve ser capaz de encontrá-las e usá-las. A magnitude do conhecimento humano não é totalmente coberta pela educação. A melhor concepção dos objetivos em educação é a de ajudar os estudantes a desenvolver ferramentas intelectuais e as estratégias de aprendizagem necessárias para a aquisição de conhecimento, permitindo que possam pensar produtivamente sobre a história, a ciência e a tecnologia, os fenômenos sociais, a matemática e as artes, para que o indivíduo tenha uma compreensão mais fundamental a respeito dos princípios da aprendizagem que podem ajudá-lo a se tornar um aprendiz vitalício e independente.

A pesquisa concernente à psicologia cognitiva ampliou a compreensão dos princípios da organização do conhecimento em que se baseiam as capacidades para solucionar problemas em diversas áreas, como matemática, ciências, literatura, estudos sociais e história. Paralelamente, os estudos de psicologia social, de psicologia cognitiva e de antropologia evidenciam que toda aprendizagem acontece em cenários que apresentam conjuntos específicos de normas e expectativas culturais e sociais, e que esses cenários influenciam a aprendizagem e a transferência de maneira marcante.

A neurociência começa a fornecer provas dos diversos princípios de aprendizagem que surgiram a partir da pesquisa de laboratório, e está mostrando como a aprendizagem modifica a estrutura física do cérebro e, por meio disso, a sua organização funcional.

Os estudos referentes ao projeto e à avaliação dos ambientes de aprendizagem envolvendo a colaboração entre psicólogos e mediadores cognitivos e de desenvolvimento 
estão produzindo conhecimento novo sobre a natureza da aprendizagem e do ensino que ocorrem em diversos cenários, sem deixar de registrar que também, as tecnologias emergentes conduzem à criação de muitas oportunidades novas - inimagináveis alguns anos atrás - para orientar e intensificar a aprendizagem.

Foi em Israel que a Bahia, em pesquisas sobre desenvolvimento cognitivo, descobriu um pesquisador contemporâneo, preocupado com o estudo da modificabilidade humana, o professor Reuven Feuerstein ${ }^{1}$ (Ph.D. em Psicologia do Desenvolvimento pela Universidade de Sorbonne, Paris). “(...) Tem-se mais potencial internalizado do que se é capaz de apresentar, podendo-se, portanto, ampliar a capacidade de aprender, desde que se tenha ferramentas cognitivas e mediação humana". [4]

A capacidade de aprender a aprender continuamente integra a concepção da Teoria da Modificabilidade Cognitiva Estrutural (TMCE), que explica a inteligência humana como um processo dinâmico, flexível e modificável, tendo como foco a adaptabilidade da espécie humana ao longo de seu percurso histórico-social, independentemente de idade, classe social e fatores genéticos, entre outros.

O Programa de Enriquecimento Instrumental (PEI), documento constituído de 14 instrumentos elaborados por Feuerstein, como um sistema aplicativo da TMCE, foi implementado em escolas do Ensino Médio da Rede Pública Estadual da Bahia com o objetivo de desenvolver, por meio da Experiência de Aprendizagem Mediada (EAM) - interação do ser humano e o seu contexto sociocultural por meio da mediação humana -, funções cognitivas e operações mentais, reunindo características que assegurassem uma autonomia de pensamento, à medida que se desenvolvessem, no indivíduo, competências, habilidades e atitudes que propiciassem o pleno desenvolvimento humano, conforme as exigências do mundo atual.

O PEI é uma ferramenta que promove experiências sócio-afetivo-cognitivas em cada um de seus Instrumentos, com exercícios que possibilitam a realização de todo um repertório de raciocínios e operações cognitivas valendo-se de linguagem verbal e não-verbal, e que, através das estratégias da EAM - Experiência de Aprendizagem Mediada - (mediação da intencionalidade e da reciprocidade, mediação do significado e mediação da transcendência), aciona o ato cognitivo subsidiado por mapas cognitivos, desenvolvendo a capacidade operativa mental do sujeito, permitindo a aquisição de pré-requisitos de apreensão, compreensão e transformação da informação pré-requisitos cognitivos de aprendizagem, fundamentos da metaleitura.

Ressalta-se que a mediação adotada como princípio educacional e aqui enfocada a partir das bases teóricas de

\footnotetext{
${ }^{1}$ Nascido na Romênia em 1921, Feuerstein estudou psicologia e pedagogia em Bucareste. Estudou também em Genebra, Suíça (quando trabalhou com André Rey e Piaget) e na Universidade de Sorbone, Paris. Atualmente, dirige o Centro Internacional para o Desenvolvimento do Potencial de Aprendizagem (ICELP/Israel).
}

Reuven Feuerstein confere a seu agente um papel de destaque e um responsabilidade correspondente. Como não se ensina aquilo que não se sabem, observa-se que o mediador de aprendizagem precisa passar pelo processo de mediação e pelo de automediação.

Exige-se do professor, um mediador por excelência e um agente de mudanças, que intervenha nos processos cognitivos de desenvolvimento do mediado, indo além do mero ensino de conteúdos, propondo estratégias de análise, síntese, comparação, classificação, estabelecimento de relações, entre outras.

\subsection{O valor de um sistema informacional}

Para que se desenvolvessem as atividades de implementação que o PEI demandava na disseminação e no uso da TMCE, a Agência de Treinamento Credenciada (ATC Bahia), autorizada pelo Hadassah, WIZO-Canada Research Institute, Jerusalém e ICELP/Israel, concebeu, implantou e coordenou o sistema de informação, constituído dos subsistemas: Administração, Formação "Competencial", Formação Continuada e Pesquisa. Esse sistema atendeu, de 1999 a 2006, a mais de 900 mil pessoas. O PEI foi experimentado por 898.015 alunos, em 281 escolas de Ensino Médio da Rede Pública de 91 municípios da Bahia, por 590 dirigentes escolares, por 6.949 professores formados em PEI.

Constituiu-se, até o momento, a maior experiência do mundo de utilização da TMCE desenvolvida pelo Professor Feuerstein em um sistema educacional público, com uma sistemática de funcionamento inédita, ou seja, não há registro de uma oferta como esta, colocada em relevância como uma ferramenta educativa, técnica e conceitual a partir de estratégias didáticas, rumo à promoção da ampliação do potencial cognitivo e à autonomia cognitiva pessoal.

Um cuidadoso e gradual planejamento, numa visão sistêmica aberta, subsidiou a implementação do PEI, seguido de um plano plurianual da ATC Bahia, que estipulou, inicialmente, duas fases para o Projeto: 1) tomada de consciência, quando ocorreram as ações de disseminação do projeto nas escolas e com outros segmentos da sociedade; 2) desencadeamento dos cursos de formação de professores do ensino médio da rede pública estadual, por 30 profissionais, formados pelo ICELP/Israel.

A gestão da ATC Bahia, por meio do subsistema administração, planejou e administrou as tarefas de suporte da implementação, a exemplo de: controle de materiais didáticos pertinentes à experiência do PEI para as unidades escolares, para os cursos de formação, experiências em PEI para professores e gestores; organização da programação de viagens dos supervisores e dos líderes executivos para os vários municípios do Estado da Bahia; controle da duplicação e distribuição dos Instrumentos; elaboração de inventário do material para as escolas e de relatório físico e financeiro mensal do Projeto para a Secretaria de Educação; elaboração e promoção da realização de contratos com clientes, entre outros. 
A Formação "Competencial”, subsistema que preparou profissionais para uma nova atitude pedagógica, respaldada pela TMCE, promoveu os cursos para formar mediadores do PEI - professores e coordenadores pedagógicos - e promoveu a experiência do PEI para dirigentes escolares.

O subsistema de Formação Continuada, responsável pela atualização constante, acompanhou e realimentou os professores que participavam dos cursos oferecidos pelo subsistema de Formação, que nos últimos anos, utilizando-se dos avanços tecnológicos, acionou-se esse subsistema na modalidade de interconexão, via fluxos eletrônicos, a exemplo do correio eletrônico.

O subsistema de Pesquisa acompanhou, avaliou e realimentou a trajetória desse novo paradigma educacional, respaldada pela TMCE, por meio de estudos experimentais, estudos de aceitação e impacto, aproximações sucessivas de escuta, análise de resultados, reunião de estudos, visando a garantia da qualidade, da fidelidade e o reconhecimento de aportes de uma linha teórica adotada.

Como se pode observar, o sistema informacional da ATC Bahia, com seus subsistemas interrelacionados, coletou, recuperou, processou, armazenou e distribuiu a informação, transformando-a em uma forma utilizável, subsidiando a coordenação da ATC Bahia na tomada de decisões, análise e visualização de assuntos complexos, resolvendo outros tipos de problemas, com a finalidade de fortalecer o planejamento, o acompanhamento e a avaliação.

\subsection{Dinâmica do sistema informacional: construindo conhecimentos e acionando deci- sões}

Em consonância com a natureza dos trabalhos a serem desenvolvidos pela ATC Bahia, durante a implementação do PEI, foi escolhido um sistema informacional com foco em soluções de problemas. Segundo Laudon (1999) [7], nas organizações, diversos fatores importantes estão, simultaneamente, envolvidos nos problemas que, por sua vez, estão sujeitos a interpretações complexas e muitas vezes controvertidas, interpretações subjetivas que envolvem visões de mundo, originadas de atores internos e externos à organização.

Um sistema informacional direcionado à solução de problemas e tomada de decisões pode ser constituído de cinco etapas de execução: identificação de problemas, período de análise e definição de problemas; entendimento do problema, momento de investigação, com coleta de fatos e mais análise, com o objetivo de um melhor entendimento; tomada de decisões, debate-se os objetivos e as soluções viáveis, e a melhor opção é escolhida; processo de projeto de soluções; por fim, período de implementação/testagem, no mundo real, das mudanças propostas e a avaliação dos resultados. [7]
A partir do ano 2000, com a ampliação da abrangência do PEI e a constante busca da qualidade da ação pedagógica, intensificaram-se as atividades do subsistema de Pesquisa, com o desenvolvimento de vários estudos avaliativos, a fim de alimentar o sistema informacional para resolver situações-problema e tomar decisões. Uma das pesquisas avaliativas constituiu-se numa tese de doutorado intitulada "Informação e Autonomia: A Mediação Segundo Feuerstein", com o objetivo de avaliar a efetividade da implementação do PEI em unidades escolares do ensino médio da rede pública estadual da Bahia, defendida em janeiro de 2003, na Universidade de Brasília. A referida pesquisa contou com a participação de toda a equipe da ATC Bahia durante o processo de coleta, tabulação e análise de dados, com a finalidade de sustentar uma linha de investigação forte e de obter um reconhecimento e visibilidade na comunidade educacional.

Desenvolvendo o plano clássico para o experimento, um estudo comparativo, a investigação foi realizada por amostra em escolas da capital e de municípios do interior da Bahia, em grupos de alunos dos turnos diurno e noturno de escolas em que houve a intervenção do PEI e em grupos de alunos de escolas que não tiveram essa intervenção.

Para alcançar o objetivo dessa investigação, foram aplicados a alunos e professores instrumentos de medidas qualitativas e quantitativas para avaliar a implementação do PEI em todo o processo: a entrada (diagnose, quando foram aplicados questionários socioeconômico e cultural, teste de Matrizes Progressivas de J. C. Raven ${ }^{2}$, séries A, B, C, D e E, pré-teste de retenção e transferência das estratégias do PEI, pré-teste de Língua Portuguesa, Matemática, História e Geografia e questionário sobre fatores impulsionadores e restritivos na sua prática pedagógica); o processo (desenvolvimento da aplicação dos Instrumentos do PEI, ocasião em que se desenvolveram ações de acompanhamento / avaliação com fichas de análise do planejamento, ficha de acompanhamento / observação de aulas) e a etapa do produto (procedeu-se à aplicação dos Instrumentos aplicados na fase da diagnose como pós-teste para avaliar o grau de modificabilidade dos indivíduos no que tange à apreensão, significação e transferência de informações).

Os resultados da pesquisa avaliativa registraram que, após a intervenção do PEI, os alunos apresentaram maior capacidade de discriminação; maior capacidade de geração de novas informações através de síntese, permutação e seri-

\footnotetext{
${ }^{2}$ Série A - processos perceptivos básicos, orientação espacial, produção de uma nova informação através do pensamento hipotético-dedutivo; Série B - mudança de sentido, relação de simetria, pensamento analógico, conduta comparativa espontânea, consideração de duas ou mais fontes de informação simultâneas; Série C progressões crescentes, progressões decrescentes, resolução de problemas, uso de duas ou mais fontes de informação simultâneas, orientação espacial, estabelecimento de relações, raciocínio hipotéticoinferencial; Série D - permutação, multiplicações lógicas, transformações; Série E - adição e subtração, verificação da capacidade de análise e síntese, conduta comparativa, reversibilidade da conduta somativa, lógica da exclusão, comparação (comum e diferente), anulação de opostos.
} 
ação; maior eficiência de pensamento relacional, hipotético-inferencial e analógico; maior eficiência de raciocínio indutivo e dedutivo; maior eficiência na análise, na síntese, na conduta comparativa; e maior potencial para abstrações e para o uso de mais de duas fontes simultâneas de informação. [16]

Nas Provas de Conteúdos de Língua Portuguesa, Matemática, Geografia e História, 84,0\% dos alunos dos grupos experimentais apresentaram aumento nas competências básicas - observar, identificar, localizar, descrever, discriminar, constatar, representar etc.; 63,0\%, aumento nas competências operacionais - classificar, seriar, ordenar, compor, decompor, conservar propriedades, fazer antecipações, calcular por estimativa, interpretar e justificar etc.; e 56,3\% dos alunos apresentaram aumento nas competências globais - analisar, aplicar, avaliar, criticar, julgar, explicar causas e efeitos, apresentar conclusões, levantar suposições, fazer prognósticos, fazer generalizações etc.

Os professores concluíram que o aluno precisava desenvolver a habilidade de identificar e resolver problemas; desenvolver o raciocínio independente; relacionar e contextualizar conteúdos curriculares a situações de vida; utilizar o trabalho sistemático e o comportamento planejado; tomar consciência de mudanças em si mesmo; e aprender a aprender. [16]

Uma outra experiência de avaliação que o PEI na Bahia realizou desde 2004 - o Tecendo a Rede -, projeto que visou avaliar a disseminação do PEI e a aplicação dos princípios da TMCE nas unidades de ensino médio da rede pública estadual através de aproximações sucessivas de escuta. De acordo com os resultados, constatou-se que os professores estavam compreendendo melhor os princípios da TMCE e, conseqüentemente, melhorando a qualidade na aplicação do PEI.

Em reuniões com Dirigentes Escolares, também no Projeto Tecendo a Rede, os diretores declararam maior compreensão dos princípios da TMCE, dando maior apoio aos professores aplicadores do PEI e compreendendo as vantagens da adoção de uma teoria de aprendizagem construtivista-interacionista para gerenciar e acionar um Projeto Político-Pedagógico, com coerência entre planejamento e ação pedagógica.

A partir de 2004, utilizou-se, como recurso para fortalecer as ações de Formação Continuada de profissionais da ATC Bahia e da rede pública de ensino médio, uma sistemática de Educação à Distância, a videoconferência, que possibilitou a otimização da disseminação dos princípios teóricos e práticos concernentes à TMCE, EAM e PEI, rumo à contextualização, à interdisciplinaridade e à significação.

O desafio dessa experiência - trabalhando com uma opção pedagógica cognitivista e interacionista com foco no processo de assimilação da informação e construção do conhecimento, processos esses, cujos resultados não são percebidos de imediato, mas a médio e a longo prazos foi a partir do pressuposto básico de que é necessário, frente à realidade atual, saber lidar com a informação e seu vasto universo, de modo a aprender continuamente. Para isso, os sistema informacional contribuiu como um grande aliado com a equipe da ATC Bahia e com a comunidade educacional.

\section{Conclusão}

A experiência em questão demonstrou que a tecnologia vem se tornando um instrumento importante na gestão da informação em educação. As tecnologias são muito promissoras, tanto para aumentar o acesso ao conhecimento como para promover a aprendizagem, podem proporcionar, ainda, extensões das aptidões humanas e contextos para interações sociais de apoio à aprendizagem, considerando-se que o processamento da informação ocorre na estrutura cognitiva, no plano mental. Ao se pensar em tecnologia, integra-se uma estrutura de suporte para a criação de ambientes de aprendizagem centradas em aprendizagem, conhecimento, avaliação e comunidade.

Neste artigo considerou-se como processamento da informação a trajetória do fluxo que ocorre na estrutura cognitiva de um indivíduo, no momento da apreensão e do armazenamento da informação no plano mental, pois a eficiência de um sistema de informação depende tanto da organização e da análise conceitual e dos documentos como das questões dos usuários. Observa-se que muitas das falhas na recuperação da informação, nos contextos atuais, se devem a desacertos ou omissões na interpretação de conteúdos e na percepção da demanda das pessoas às quais se destina o sistema informacional. Portanto, a recuperação da informação está relacionada com as formas de armazenamento e estas por sua vez com o tratamento e a organização da informação.

Diante do exposto, ao se trabalhar com sistemas de informação na área de educação, alguns pontos de reflexão merecem destaque:

- Uma das principais características da nova ciência da aprendizagem é o foco nos processos do conhecimento. Os seres humanos são vistos como agentes guiados por objetivos que procuram informação de modo ativo. [14 e 17]. Chega-se à educação formal com uma série de conhecimentos, habilidades, crenças e conceitos prévios que influenciam significativamente $\mathrm{n}$ a percepção sobre o meio ambiente e no modo de organizar e interpretar essa percepção.

- Defende-se a existência de uma extensão lógica de que o novo conhecimento deve ser elaborado a partir do conhecimento existente e que os professores precisam prestar atenção aos entendimentos incompletos, às falsas crenças e às interpretações ingênuas dos conceitos que os aprendizes trazem consigo sobre determinado assunto, ratificando-se que o ponto de partida para o entendimento e para a construção do novo conhecimento será o conhecimento existente. [1]

- A necessidade de organizar o conhecimento sempre foi reconhecida pelo homem a partir de bases em u- 
nidades de conhecimento, que não são outra coisa senão conceitos, que por sua vez se compõe de elementos que permitem que um sistema de conceitos seja construído da mesma forma como um sistema de organização do conhecimento. Dessa maneira, a representação do conhecimento é a chave para a recuperação e disseminação efetiva dos dados, informação e conhecimento. [1]

- O princípio da incerteza integra as concepções do mundo atual. E essa incerteza diminui à medida que ocorre o aprendizado, quando novos conhecimentos são incorporados à cognição, o que remete à construção do conhecimento como atividade humana, como capacidade de alterar estruturas, criar novos modelos mentais. O foco está no sujeito nos processos de compreensão da informação e no uso que o ele faz da informação em situações diversas.

- As diferenças instrucionais tornam-se mais evidentes quando avaliadas com base na perspectiva de como o aprendizado é transferido a novos problemas e cenários. A capacidade das pessoas de transferir o que aprenderam depende do aprendizado inicial. Vale considerar que a aprendizagem de um assunto complexo é demorada, e as avaliações a respeito da transferência devem considerar o grau entendimento do aprendizado original. [1]

- A transferência é um processo ativo. Todo aprendizado, até mesmo o inicial, envolve a transferência de experiências anteriores. A transferência não

\section{Referências}

[1] BRANSFORD, John D.; BROWN, Ann L.; COCKING, Rodney R. Como as pessoas aprendem: cérebro, mente, experiência e escola. Trad. Carlos David Szlak. São Paulo : Senac, 2007.

[2] CERVERÓ, Aurora Cuevas. Alfabetización em información y lectura em los Nuevos entornos educativos. In: Alfabetização Digital e Acesso ao Conhecimento / Org. Antonio Miranda e Elmira Simeão.

[3] DECLARACIÓN de Praga : hacia una sociedad alfabetizada informacionalmente. [S. 1.: s.n.], 2003. Disponible en castellano, catalán, euskera y gallego en: $<$ http://www.codbc.org/grups/alfincat/documents.html $>$.

[4] FEUERSTEIN, Reuven. Instrumental enrichment: an intervention program for cognitive modifiability. Baltimore, Md.: University. Park Press, 1980. 436 p.

[5] FEUERSTEIN, Reuven. The coherence of the theory of modifiability. In: KOZULIN (Ed.). The ontogeny of cognitive modifiability : applied aspects of mediated learning \& experience of instrumental enrichment. Jerusalem: ICELP, 1997.

[6] GRÀCIA, Josep Vives i. La alfabetización informacional: una alfabetización pediente en la era digital. In: é simplesmente algo que pode ou não aparecer depois da ocorrência do aprendizado inicial. Às vezes o conhecimento trazido pelas pessoas a uma nova situação impede o aprendizado subseqüente, pois encaminha o pensamento a direções erradas. [1]

Um sistema de informação educacional otimiza a gestão da informação e, por conseqüência, a gestão organizacional. Na experiência educacional da ATC Bahia, o registro e o processamento de dados e informações justificam-se em razão do fomento de novas descobertas, de novos conhecimentos. Não obstante algumas dificuldades encontradas para acionar esse sistema de informação - singularidade do projeto (primeiro no mundo num sistema público como política educacional); dimensão (extensão territorial do Estado e quantitativo de pessoas envolvidas); formação do professor (formação com foco no conteúdo, resultado do currículo dos cursos de formação); resistência do professor à mudança (no planejamento, na metodologia e na avaliação); e quebra de paradigma (compreensão da TMCE e sua contextualização) - ele atendeu ao objetivo de disseminar informações para a tomada de decisões, a partir da detecção e análise de problemas em prol do fortalecimento da educação.

Ratifica-se, portanto, a necessidade de, frente à realidade educacional, saber lidar com a informação, saber como definir suas necessidades informacionais, como buscar e acessar a informação, como avaliá-la, organizá-la, transformá-la em conhecimento, habilidade e valor que determinam diferentes formas de interação com o mundo.

Alfabetização Digital e Acesso ao Conhecimento / Org. Antonio Miranda e Elmira Simeão.

[7] LAUDON, Kenneth C.; LAUDON, Jane Price. Sistemas de Informação com internet. Tradução de Dalton Conde de Sérgio Alencar. 4. ed. Rio de Janeiro: LTC, 1999.

[8] MARZAL, Miguel Ángel. Documentación y tecnologías de la información : herramientas para la alfabetización en infrmación y organización de recursos didáticos. In: Alfabetização Digital e Acesso ao Conhecimento / Org. Antonio Miranda e Elmira Simeão.

[9] MASETTO, M. (Org.). Docência na Universidade. Campinas: Papirus, 1998.

[10] MCGGE, James; PRUSAK, Laurence. Gerenciamento estratégico da informação. Tradução de Astride Beatriz de Figueiredo. 6. ed. Rio de Janeiro: Campos, 1994.

[11] MORAES, et al.. Sociologia. In: BRASIL. Ministério da Educação, Secretaria de Educação Básica - SEB, Departamento de Políticas de Ensino Médio. Orientações Curriculares do Ensino Médio. Brasília, 2004.

[12] MORIN, E. Sobre la interdisciplinaridad [recurso eletrônico]. Revista Complejida, 1995, año 1, n. 0. http://pensamientocomplejo.com.ar/docs/files/morin $\% 5$ so bre\%5Finterdisciplinaridad\%2Epdf [consulta: 30/01/2007]

[13] MUSA, E. V. Prefácio. In: CASALLI, A. et. al. (Org.). Educação e empregabilidade: novos caminhos da aprendizagem. São Paulo: EDUC. 1997. 
[14] PIAGET, Jean. O nascimento da inteligência na criança. Rio de Janeiro: Guanabara, 1987.

[15] TARAPANOFF, Kira (Org.). Inteligência organizacional e competitiva. Brasília: Ed. Universidade de Brasília, 2001.

[16] VARELA, Aida Varela. Informação e autonomia: a mediação segundo Feuerstein. 2003. Tese (Doutorado) -, Departamento de Ciência da Informação e Documentação, Universidade de Brasília, Brasília, 2003.

[17] VIGÓTSKI, L. S. A formação social da mente (São Paulo: Martins Fontes, 1991.

[18] WALKER, G. The information environment: a reader. New York: G. K. Hall, 1992.

\section{Os autores:}

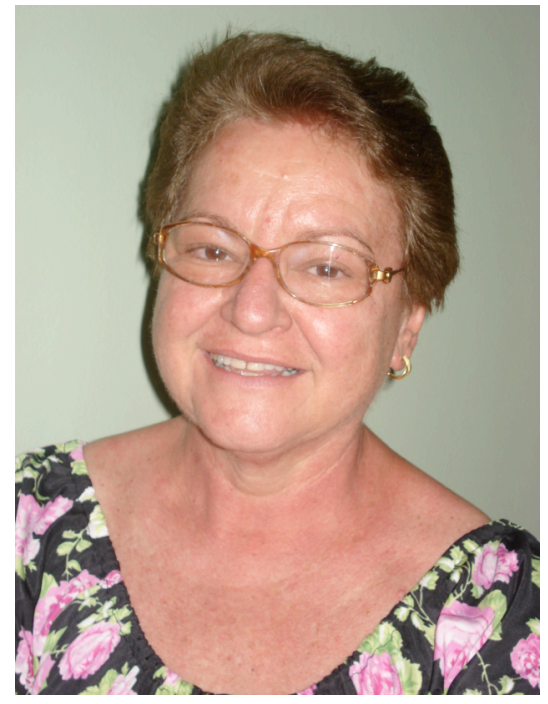

1 Aida Varela Varela - Especialista em PEI e Doutora em Ciência da Informação, Docente da Universidade Federal da Bahia (UFBA). Gerenciou o Departamento de Pesquisa da ATC Bahia / Fundação Luís Eduardo Magalhães, responsáveis pela implantação / implementação do PEI no Estado da Bahia. Endereço: Rua Jardim Concórdia, n. ${ }^{\circ} 89$, Castro Neves - Brotas. Salvador / Bahia. CEP: 40.255-070

E-mail: varela1946@hotmail.com,varela@ufba.br

Telefones: (71) 3244-2772 / 9917-8528



2 Igor Baraúna Guimarães - Graduado em Letras pela Universidade Católica do Salvador (UCSal), graduando em Jornalismo pela Faculdade da Cidade do Salvador. É orientando de Iniciação Científica pelo PIBIC / UFBA. Possui cursos de Vivência do PEI, níveis I e II. Foi Assistente Técnica do Departamento de Pesquisa da ATC Bahia / Fundação Luís Eduardo Magalhães, responsáveis pela implantação / implementação do PEI no Estado da Bahia. Endereço: Praça Catarina Paraguassu, n. ${ }^{\circ}$ 07, Periperi. Salvador / E-mail: igor.guimaraes@hotmail.com Telefones: (71) 3397-1628 / 9926-3496 